\title{
Whose News? \\ Class-Biased Economic Reporting in the United States
}

\author{
Alan M. Jacobs* \\ Professor, \\ Department of Political Science, \\ University of British Columbia \\ alan.jacobs@ubc.ca \\ (D) 0000-0002-1008-2551
}

Timothy Hicks

Associate Professor,

School of Public Policy,

University College London

t.hicks@ucl.ac.uk

(D) 0000-0001-6012-8418
J. Scott Matthews

Associate Professor,

Department of Political Science, Memorial University of Newfoundland scott.matthews@mun.ca

(D) 0000-0001-9738-3447

Eric Merkley SSHRC Postdoctoral Fellow, Department of Political Science, University of Toronto eric.merkley@utoronto.ca

(D) 0000-0001-7647-9650

February 19, 2021

Conditionally accepted at the American Political Science Review 


\begin{abstract}
There is substantial evidence that voters' choices are shaped by assessments of the state of the economy and that these assessments, in turn, are influenced by the news. But how does the economic news track the welfare of different income groups in an era of rising inequality? Whose economy does the news cover? Drawing on a large new dataset of U.S. news content, we demonstrate that the tone of the economic news strongly and disproportionately tracks the fortunes of the richest households, with little sensitivity to income changes among the non-rich. Further, we present evidence that this pro-rich bias emerges not from pro-rich journalistic preferences but, rather, from the interaction of the media's focus on economic aggregates with structural features of the relationship between economic growth and distribution. The findings yield a novel explanation of distributionally perverse electoral patterns and demonstrate how distributional biases in the economy condition economic accountability.
\end{abstract}

\title{
Introduction
}

The news media play a powerful role in informing citizens' judgments of the impact of government activity. This is especially true in relation to evaluations of the economy (Hetherington 1996; Boydstun, Highton, and Linn 2018) - a massive and multi-dimensional phenomenon in regards to which direct experience may be of limited relevance (Mutz 1992). Voters' electoral choices are, in turn, profoundly influenced by their assessments of the state of the economy (Lewis-Beck 1988; Duch and Stevenson 2006). But what is the nature of the economic reality presented by the media? Scholars have made some progress on the issue, exploring the news media's differential responsiveness to levels and changes of various economic parameters (Soroka 2006, 2012; Soroka,

${ }^{*}$ Jacobs, Matthews, and Hicks rotate author orderings across their joint papers to reflect equal contributions among themselves.

${ }^{\dagger}$ The authors acknowledge the generous support of the Social Sciences and Humanities Research Council of Canada (Grant \#435-2014-0603). Hicks gratefully acknowledges financial support from a Leverhulme Trust Research Fellowship (RF-2017-227\7). We are grateful to Keith Banting, Erik Bleich, Martin Gilens, Aaron Hoffmann, Torben Iversen, Mark Kayser, Paul Kellstedt, Mark Pickup, Jonas Pontusson, David Rueda, Stuart Soroka, Katerina Tertytchnaya, Laurel Weldon, and Lori Young for very helpful comments on earlier drafts. We also benefited greatly from feedback from audiences at the 27th Annual Conference of the Society for the Advancement of Socio-Economics, London (2015), the American Political Science Association Annual Meeting, Philadelphia (2016), a workshop on "Social and Political Inequality" at the Vienna University of Economics (2016), the Canadian Political Science Association Annual Meeting, Vancouver (2019), the University of Gothenburg, the University of Zürich, the University of Konstanz, the University of Cologne, the University of Mannheim, the Hertie School of Governance, and Simon Fraser University. Alberto Alcaraz, Emily Beatty, Rachel Darby, Abu Kamat, Emil Lauritsen, Katie Lay, Leise Sandeman, Arian Zand, and Amy Zhang provided invaluable research assistance. We thank Johanna Dunaway for access to her newspaper ownership data. 
Stecula, and Wlezien 2015). What we know little about, however, is whose material welfare the economic news reflects. In particular, how responsive is economic reporting to developments affecting different income groups? When voters turn to the news media for an assessment of economic performance, does the signal that they receive reflect the fortunes of most households or of those located at particular points in the income distribution - whether the middle, the bottom, or the top?

We argue in this paper that the economic news in the United States has, over the last 40 years, painted a portrait of the economy that strongly and disproportionately tracks the welfare of the very rich. Analyzing a vast, original dataset of news articles from 32 high-circulation U.S. newspapers over this period, we uncover clear evidence that reporting on the U.S. economy is descriptively class-biased. ${ }^{1}$ Specifically, the evaluative content of economic news becomes more positive (negative) in periods in which the incomes of the very rich grow (shrink), and is largely uncorrelated with change in the incomes of less well-off Americans, once growth in incomes at the top is taken into account. Put simply, good economic news tracks, above all, the fortunes of the most affluent.

We then seek to understand how this pattern arises. Rather than reflecting a conscious journalistic bias in favor of the interests of the very rich, class-biased economic news, we argue, stems largely from the media's focus on charting economic performance in the aggregate. Central to our account is the breakdown, over the past forty years, of the relationship between aggregate economic growth and the welfare of the average American. In the first few decades after World War II, aggregate growth and employment were strongly correlated with the incomes of lowerand middle-income Americans. Since the mid-1980s, however, aggregate economic expansion and contraction have been far more closely tied to the rise and fall of top incomes than to changes in the incomes of the non-rich, likely because of changes in the underlying drivers of growth itself. Moreover, top-end inequality has become a procyclical phenomenon, rising when the economy as a whole is doing well and falling when aggregate performance flags.

This macroeconomic pattern has profound consequences for the informational context in

\footnotetext{
${ }^{1}$ We follow the nomenclature of "class-biased economic voting" coined by Bartels (2008), but acknowledge that standard sociological approaches to class are not purely income-based.
} 
which citizens operate. The fact that the distribution of growth is itself upwardly skewed means that economic reporting focused on economic aggregates yields a news environment that most powerfully reflects gains and losses for the most affluent members of society. Class-biased economic news, in short, emerges from journalistic efforts to track the ups and downs of the business cycle in the context of an economy that distributes income growth in powerfully class-biased ways.

Consistent with our argument, we show that the correlation between economic news tone and growth in top incomes largely disappears once indicators of aggregate expansion and contraction are accounted for. Further, in examining the distribution of media attention to distinct economic phenomena, we find that aggregate expansion - and its correlates, like employment and corporate performance - are far more likely to be mentioned than phenomena related to the distribution of income or wealth. We also show that class-biased dynamics in economic news tone are generic across media outlets varying in ownership structure and partisan orientation. This finding suggests that class-biased economic news reflects a pervasive understanding of the economy as an aggregate phenomenon, rather than a cognitive shortcut for time-pressured reporters in profit-centered newsrooms or an ideological preference imposed by owners, editors, or consumers.

Beyond its direct findings, the analysis below highlights a weak link in the chain of electoral accountability. To the extent that voters' perceptions of the national economy are shaped by the media (Hetherington 1996; Boydstun, Highton, and Linn 2018; Nadeau et al. 1999; Soroka 2006), the "economy" on which most voters have been voting has, in an important sense, not been theirs. This dynamic helps to explain puzzling patterns uncovered in previous political economy research. The results suggest an explanation, for instance, of why incumbents presiding over sharp increases in economic inequality in the United States have not been penalized at the ballot box (Bartels 2008; Hacker and Pierson 2011; Hicks, Jacobs, and Matthews 2016).

To the extent that the paper's results travel, moreover, they suggest a novel explanation of the broader disconnect between levels of inequality and levels of redistribution (Milanovic 2000; Kenworthy and McCall 2008; Kelly and Enns 2010). Where the fruits of economic expansion are captured largely by the most affluent, a news media focused on economic aggregates will 
spawn an informational environment that directly undercuts non-rich citizens' pursuit of their distributive interests. This suggests, in turn, important interactions between mass political behavior and comparative political economy. For example, where production regimes (Hall and Soskice 2001) or growth models (Baccaro and Pontusson 2016) spread macroeconomic gains and losses broadly, the average citizen may be well served by a news environment that signals how well the economy as a whole is doing. But forms of capitalism that decouple the welfare of most households from aggregate growth create different informational requirements for economic accountability - requirements to which prevailing patterns of economic reporting may be poorly suited.

\section{Mechanisms of Class-Biased Economic News Coverage}

In referring to "class-biased" economic news, we refer to a differential in the correlation of the valence of economic news with the economic welfare of different socioeconomic groups. Given empirical trends in the income distribution since the 1970s, our specific focus is on news responsiveness to the fortunes of the very rich as compared to the rest of the population. Of particular interest is the possibility of an upward bias: one in which the tone of news coverage of the economy is more strongly associated with the welfare of the very rich than that of the non-rich.

Prior work on bias in news coverage has focused on a range of sources. These include the economic interests of corporate owners (e.g. Herman and Chomsky 1988; Gilens and Hertzman 2000), the upper-middle-class composition of the journalistic profession (e.g. Gans 2004), and the ideological preferences of news audiences (e.g. Gentzkow and Shapiro 2010). A central, shared feature of these varied accounts is their focus on the interests or preferences of producers or consumers of the news. Economic or partisan bias in media content, in these accounts, arises from the disproportionate influence on that content of actors with particular material interests or ideological worldviews.

In contrast, the argument that we advance here focuses on an implicit source of bias in economic news coverage, one that emerges from the interaction between ostensibly neutral jour- 
nalistic practices and structural biases in the drivers of economic growth.

\section{Covering the "Business Cycle"}

We posit the operation among journalists of an understanding - a "mental model" - of the economy that positions the promotion of aggregate expansion as the central, if not exclusive, objective of economic management. In his classic study of American newsrooms, Gans (2004) finds that "responsible capitalism" is among the core values of American journalism and that, in economic reporting, "[e]conomic growth is always a positive phenomenon" (46). "Good" and "bad" economic news, then, are defined by developments that signal or reflect an upturn or a downturn, respectively, in the business cycle especially in output and its close correlate, employment. In this framework, moreover, distributional questions as such are generally not salient, on the assumption that the benefits of economic growth are typically broadly distributed: as the aphorism goes, "a rising tide lifts all boats."

Understanding economic performance as a primarily aggregate-level phenomenon, reporters can be expected to focus on broad indicators of economic expansion and contraction, such as GDP growth and the unemployment rate. They may also attend to an array of indicators understood to be predictors or symptoms of aggregate growth. Given a common view of "business conditions" as a core economic foundation, we would expect corporate earnings and valuations (share prices) to receive special attention. The continuous movement of the stock market is likely to be a particular focus of economic coverage given that it seemingly provides a daily update on the overall health of the economy, playing to journalistic interest in novelty and change (Soroka, Stecula, and Wlezien 2015). Importantly, reporting on market indices or corporate profits need not be motivated by any specific concern with those most directly affected - e.g., shareholders - since these indicators are thought to shed light on the general state of the economy. As Gans (2004) aptly notes, "when anchormen gave the stock market report, even the most detached ones looked cheerful when the market had had a good day, assuming this to be of universal benefit to the nation and the economy" (46). 
How might a journalistic focus on economic aggregates generate a class bias in economic news? In principle, it need not. When economic gains and losses are equally distributed, a focus on the business cycle will be equally sensitive to the fortunes of all income groups. However, there is strong reason to believe that, in recent decades, a journalistic tendency to view growth and employment as ultimate yardsticks of economic performance would tend to generate class-biased economic news.

\section{Aggregates and Distribution in the U.S. Economy Since 1980}

For much of the postwar era, aggregate growth and employment were relatively closely related to the incomes of the non-rich. Yet this relationship appears to have broken down over the last 35 years. Among the early work recognizing the emerging disconnect was a paper by Cutler and Katz (1991), who noted that the economic expansion of 1983-1989 was accompanied by rising inequality in the distribution of income and minimal poverty reduction. For the 1947 to 1989 period, Cutler and Katz find low unemployment to be strongly associated with rising income shares for the bottom three quintiles and falling shares for the top two. However, after 1983, incomes in the bottom quintile fell between 0.5 and 1.0 percentage points more than macroeconomic variables would predict, given average postwar relationships, while incomes in the top quintile rose by between 1 and 4 percentage points more.

More recent work has confirmed that, over multiple business cycles, it is the very rich whose fortunes rise fastest and fall most steeply with the business cycle. Guvenen, Ozkan, and Song (2014) find that in the recessions of 2000-2002 and 2007-2010, while the poor suffered more than those with middle incomes, the (pre-recession) richest 1 percent saw sharper income drops than any group in the bottom 99 percent. At the trough of the Great Recession, in 2008, percentage losses for the top 1 percent were about double that for the median earner, while losses for the top 0.1 percent were about three times as large (see also Wiczer 2014). Since 1985, a 1 percentage point drop in GDP growth has been correlated with a 4.55 percent drop in the incomes of the top 0.1 percent, but a 1.08 percent increase in the income of the median earner. Similar findings hold for unemployment: a one-point rise in the male unemployment rate is associated with an 
average income loss of 6.87 percent for the top 0.1 percent, but only a 1.77 percent loss at the median (Guvenen, Ozkan, and Song 2014). The very rich also gain more than the median earner during expansions. During the 1993-2000 and 2002-2007 upswings, the incomes of the top 1 percent grew by 98.7 percent and 61.8 percent, respectively, while the incomes of the bottom 99 percent grew by only 20.3 percent and 6.8 percent, respectively (Saez 2016). Bivens and Shierholz (2018) likewise point to cyclicality in inequality, showing that the wages of the bottom 90 percent of earners rose as a share of personal income, from 45.8 to 51.1 percent, during the Great Recession and then fell back to 46.6 percent in 2015 as the economy recovered.

Why have top incomes become exceptionally sensitive to aggregate fluctuations? Explanations are contested, but several studies point to changes in the distribution of demand for skills driven by trade and technical change. Cutler and Katz (1991) argue that, during the recovery of the 1980s, while aggregate employment rose - a phenomenon that, on its own, would have benefited lower-paid workers - this aggregate development was overwhelmed by an increase in relative demand for higher-skilled labor, generating a net increase in wage dispersion and income inequality. Aghion, Caroli, and Garcia-Penalosa (1999) contend that technological change, especially the spread of general-purpose technologies, has become a key driver of both economic growth and earnings inequality by creating a growing skill premium, particularly as the supply of higher-end skills fails to keep pace with demand (see also Goldin and Katz 2007; Parker and Vissing-Jorgensen 2010). The political economy literature also points to factors such as the increasing financialization of the economy (Lin and Tomaskovic-Devey 2013) and the decline of labor unions (Volscho and Kelly 2012) that might have simultaneously driven higher rates of economic growth and higher concentrations of income at the top.

It is, moreover, not hard to see why journalists' prevailing mental models might be insensitive to these recent distributional dynamics. For one thing, making sense of distribution is far more complex than tracking economic aggregates; while aggregates move only up or down, distribution is intrinsically multi-dimensional. Second, distribution implicates contested values about who should win or lose, and by how much, while there has generally been broad consensus on the merits of high growth and low unemployment. Further, for the first decades of the postwar era, 
a focus on economic aggregates worked: the key indicators of growth and employment had an excellent track record in capturing broad welfare gains and losses (Cutler and Katz 1991). To the extent that mental models are "sticky," it is not surprising that journalists' "growth-is-good" outlook has survived changes in the underlying structure of the economy that were themselves difficult to observe.

In sum, the relationship between the U.S. macroeconomy and distribution over the last quarter-century implies that the tone of news focused on economic aggregates, like growth and unemployment, will be characterized by a bias toward the interests of the very rich - even without any conscious intention, on journalists' part, to deliver a skewed portrait of the economy. To the extent that growth and wage inequality arise from a common source, "good" economic times understood in aggregate terms - will tend to be accompanied by rising concentrations of income at the top. We should, on this logic, expect economic news focused on the business cycle to more closely track the incomes of the very rich than the incomes of the non-rich, and we should expect the news to become more positive as income inequality - understood as an income skew toward the top - rises. Given the steep concentration of company shareholding among the very rich, ${ }^{2}$ economic assessments tied to corporate or stock market performance will likewise be disproportionately correlated with welfare at the top of the income scale.

This argument does not imply that class-biased economic news emerges apolitically or by pure chance. Political choices in areas such as trade, education, labor relations, and taxation have likely played a major role in tying growth and inequality more closely together in the U.S. in recent decades (see, e.g., Hacker and Pierson 2011). Our claim, however, is that class-biased economic reporting itself need not involve any deliberate effort by reporters to over-attend to the interests of the rich. Given the underlying distributional biases in the broader political economy, the emergence of class-biased news merely requires that journalists cheer the economy on during periods of aggregate growth and lament its decline in aggregate downturns.

\footnotetext{
${ }^{2}$ Among the top 1 percent of earners in $2013,92.8$ percent owned $\$ 5,000$ or more in stocks, while only 30.3 percent of those in the middle 3 income quintiles did. 76.6 percent of the top 1 percent, and only 6.6 percent of the middle 60 percent, were business owners (Wolff 2016).
} 


\section{Causal Models}

We can usefully formalize our core argument as a simple structural causal model (Pearl 2009):

$$
\text { NewsTone } \leftarrow \text { GrowthAndEmployment } \leftarrow \mathbf{X} \rightarrow \text { Inequality }
$$

where $\mathbf{X}$ denotes a set of inequality-inducing drivers of growth and employment (e.g., trade or skill-biased technological change). In this model, the drivers of growth simultaneously generate aggregate expansion and higher inequality (i.e., higher income shares for the very rich). Economic aggregates, in turn, drive the positivity of economic news, resulting in a positive correlation between inequality and news tone. Class-biased news arises here from media actors placing a positive value on features of the economy that are systematically correlated with rising inequality, owing to common causes of these features of the economy and rising inequality.

We have further argued that, in search of indicators of the overall health of the economy, journalists are likely to pay particular attention to gauges of corporate performance, such as corporate profits and stock-market developments, yielding the following data-generating process:

$$
\text { NewsTone } \leftarrow \text { CorporatePer formance } \rightarrow \text { Inequality }
$$

Again, a positive correlation between news tone and inequality emerges from their common cause, corporate performance itself. ${ }^{3}$

We return to these causal models later in the article, when we test empirical predictions of the "covering the business cycle" mechanism. ${ }^{4}$

\footnotetext{
${ }^{3}$ One subtle structural difference between Model 1 and Model 2 is that, in the former, it is the underlying drivers of growth and employment that cause inequality, while in the latter the phenomenon that drives news tone is itself a cause of inequality.

${ }^{4}$ Note that we do not seek to estimate all relationships implied by the model, focusing on those germane to the paper's argument.
} 


\section{Measuring Economic News Tone}

The cornerstone of this paper's analyses is an over-time measure of economic news tone that we develop from a large set of high-circulation U.S. newspapers. Here we describe the construction and validation of this measure. ${ }^{5}$

We measure the tone of the economic news reported in newspapers because of the availability of a longer time series of content for a larger number of sources than would be available for other media, such as broadcast or cable TV news or news websites. Newspapers were selected for inclusion based on three criteria. First, as we aim to characterize the news environment inhabited by the American voter, our news sources had to collectively capture a substantial share of the media environment. We thus focused on high-circulation newspapers, specifically those in the top 50 in circulation numbers based on data from the Alliance for Audited Media (AAM). Second, the sources had to be available for download as full text via Lexis, Lexis-Nexis Academic, or Factiva. Third, newspapers had to be available over a sufficiently long period of time to enable well-powered time series analysis. Thus, we set a text-availability start-date cutoff of 1994. A total of 32 newspapers met these criteria and entered our sample. Based on historical circulation data from AAM, the newspapers comprising our tone measure accounted for 36.3 percent of total weekly paid print circulation in $2012 .^{6}$

We began by selecting all stories from these newspapers, across the time period for which content was available, that mention the word "economy" or "economic" in the body of the text, along with a mention of the United States or any of the states. The full downloaded sample contained 2,460,000 articles.

Our data allow us to further restrict the sample of articles in helpful ways. ${ }^{7}$ First, we excluded articles that appeared in the business section because this section (a) is less likely to be read and

\footnotetext{
${ }^{5}$ Replication materials are available from this journal's Dataverse (Jacobs et al. 2021). There are two sets of online Supplementary Materials for this article, A (accessible together with this article) and B (accessible with the replication materials). Section, table, and figure labels (e.g. A1 or B3) indicate item location.

${ }^{6}$ We use AAM's average daily, paid, print circulation figures for 772 newspapers as of 2012, estimating, for each newspaper, total weekly circulation as the sum of that paper's average daily circulation. The year 2012 is the closest to the center of our time series available in AAM data.

${ }^{7}$ Supplementary Table B1 summarizes the effects of these sample restrictions on article numbers.
} 
(b) focuses on the stock market and corporate earnings, which would likely bias results toward a finding of class-biased media responsiveness. Second, we used a machine-learning approach to classify articles as being predominantly about economic developments in the U.S., focusing on the headline and first 400 characters of each article (denoted as "Lede-relevant"), ${ }^{8}$ and then restricted the sample on this basis. The aim of this procedure was to reduce the sample's share of false positives, i.e., articles that contained one of our search terms but were not about the U.S. economy.

We measure the sentiment of economic news using a dictionary-based method that evaluates tone by counting negative and positive words. Past work has measured tone in economic news by simply counting the word "recession" (e.g. Blood and Phillips 1995) or by using a small basket of positive or negative economic terms (Hopkins, Kim, and Kim 2017). Our measure of tone was constructed by applying the Lexicoder Sentiment Dictionary (LSD) to our sample (Young and Soroka 2012). This dictionary, which contains 6,016 words coded for positive and negative connotations, together with the Lexicoder program, yields counts of positive and negative words for each article. Each article was given a tone score, defined as Tone $=[$ (number of positive words) - (number of negative words)]/(total number of words). This score captures the general "charge" of the article, while adjusting for the amount of neutral content. In effect, the approach measures the intensity of positive or negative sentiment by comparing the prevalence of words that are in each category to the prevalence of words in that are in the other category and that are neutral in tone. This operationalization rests on the assumption that, within the scope of analysis, the positivity or negativity of words in the dictionary is constant over time and across space, and that, in absolute terms, all positive and negative words contribute equally to the tone of the text. Notwithstanding these caveats, the LSD has been found to generate comparable results to those produced by human coders when applied to news content (Young and Soroka 2012), and it appears to outperform simpler dictionaries (Soroka, Stecula, and Wlezien 2015), although recent work has found that further performance gains are possible with supervised machine learning methods, at least when optimal choices are made regarding the construction of the training set (Barberá et al. 2021). Importantly, an LSD-based measure of economic news

\footnotetext{
${ }^{8}$ Full details of the procedure and classifier performance are in Supplementary Section B1.
} 
has also previously been shown to be correlated with the unemployment rate (Soroka 2012).

Finally, to generate sample sizes within units that minimize noise, and to align with the temporal units for which economic variables are observed, we aggregate article-level Lexicoder scores up to newspaper-quarter mean tone scores. Figure 1 conveys a sense of the temporal variation in the resulting tone variable, plotting the by-quarter circulation-weighted mean of the variable through our sample period. ${ }^{9}$

The series has face validity in that it broadly tracks our intuitions about macroeconomic dynamics in the United States during the sample period, with dips around the periods of recession (indicated by vertical shading). In Supplementary Section A2, we provide a more systematic assessment of the validity of our news tone measure. We do so by asking whether the measure is correlated with other phenomena with which it should be correlated. First, we show that the measure is strongly correlated with an independent proxy for economic news tone, a Surveys of Consumers (SoC) item asking about the favorability or unfavorability of information that respondents have recently received about business conditions. Second, using two additional SoC items, we demonstrate that the tone measure is well correlated with phenomena on which a range of prior studies suggest that the economic news has an effect: mass perceptions of business conditions and evaluations of the government's handling of the economy. ${ }^{10}$ We show, additionally, that these relationships hold not only in "naive" estimations of the correlation, but also in a set of models in which we factor out a range of possible alternative sources of a correlation between news tone and the benchmark variables. We demonstrate, further, that the associations between news tone and the benchmark variables are strong not just for the SoC sample as a whole, but specifically for respondents in the bottom and middle income terciles socioeconomic groups of particular normative importance for this paper's analysis. Finally, we use estimates from a pair of reduced-form vector autoregression models to show that it is very unlikely that the observed association between news tone and economic perceptions is the result of the latter's effect on the former (cf. Hopkins, Kim, and Kim 2017).

\footnotetext{
${ }^{9}$ This figure is illustrative only, as it does not account for newspapers' entry and exit from the sample over time.

${ }^{10}$ For prior evidence on this association, see, e.g.: Boydstun, Highton, and Linn (2018), De Boef and Kellstedt (2004), Garz and Martin (2020), Merkley (2019), and Soroka, Stecula, and Wlezien (2015).
} 


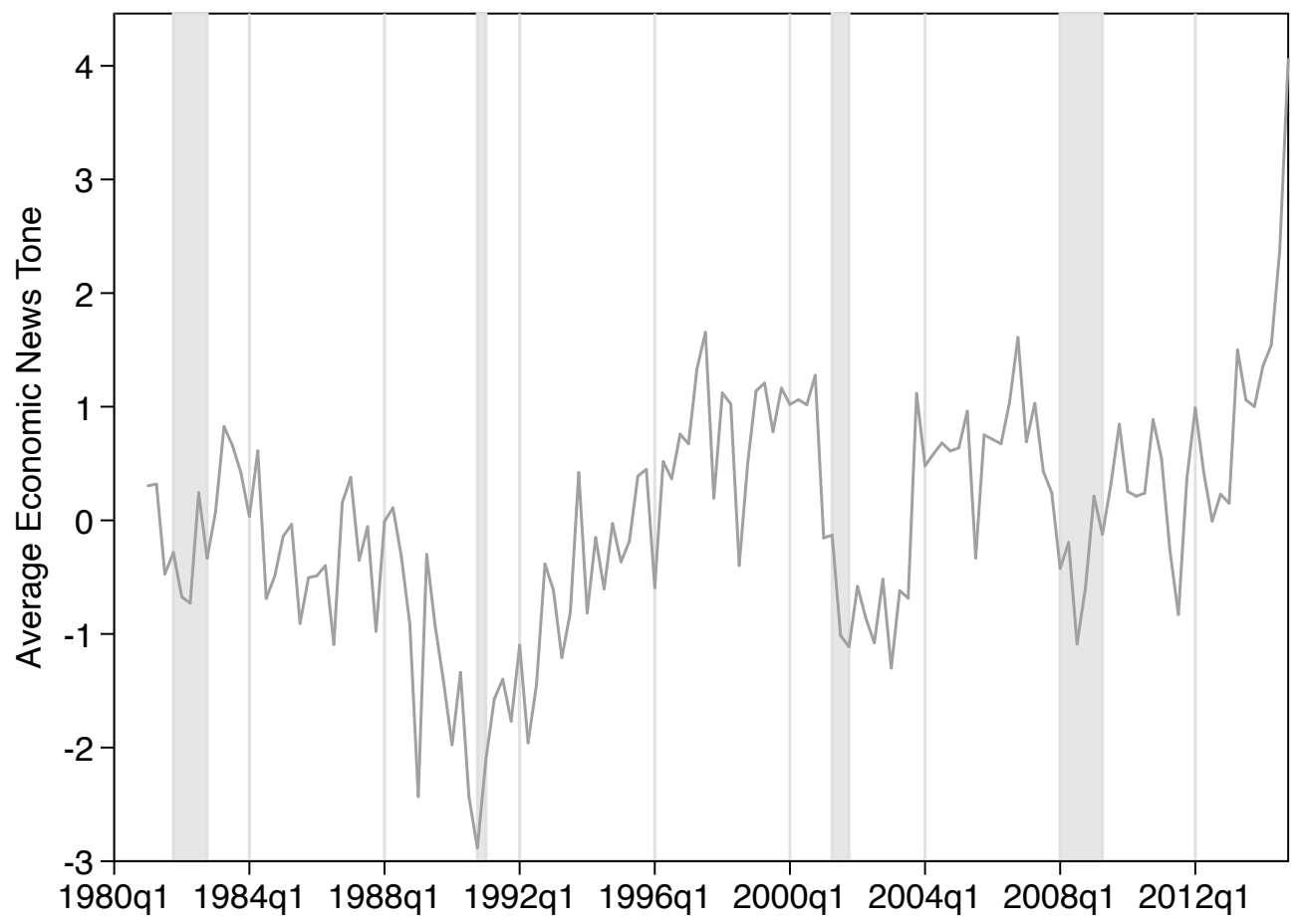

Figure 1: Time series plot of mean of standardized, circulation-weighted quarterly measure of tone of newspaper economic reporting. Vertical shading indicates recessionary period as defined by FRED database series (USRECQ).

\section{National Descriptive Patterns}

We now turn to the paper's core descriptive concern: does good (bad) economic news tend to appear in periods of broad economic gains (losses) or, rather, in periods when gains (losses) are concentrated on particular income strata? While causal matters occupy our attention in the next section, this prior, descriptive question is of central importance for the workings of democratic accountability. To see why, suppose that voters on average receive more positive economic news in periods of relative gain for the very rich than they do during periods of broadly shared prosperity. If economic news tone affects mass perceptions of the economy and, in turn, votes, then in this situation citizen evaluations and electoral outcomes will tend to reward incumbents who deliver pro-rich economic distributions relative to distributions that allocate gains more equally. The informational environment will be pushing non-rich voters to vote, in effect, against their own income groups' economic interests. That is the case, moreover, regardless of what forces are causing the correlation between distribution and tone. 
To assess the descriptive patterns of interest, we estimate a series of regression models in which economic news tone is the dependent variable and our core regressors are income growth rates in various parts of the income distribution. Specifically, we use growth in pre-tax income from the World Inequality Database (WID.world) constructed by Alvaredo et al. (2017). WID.world incorporates the former World Top Incomes Database (Piketty and Saez 2003), which has been widely used across the social sciences. ${ }^{11}$ WID. world combines administrative data (e.g., personal income tax records), household survey data, and national accounts data (particularly national-income estimates) to provide long time-series of information on annual income levels at many points in the U.S. national income distribution, including coverage of top-income categories that are poorly captured in purely survey-based estimates. ${ }^{12}$ We use these estimates to construct mean-income growth rates for a large range of income deciles, quintiles, and various subsets of the top decile of the distribution.

The WID.world income variables are measured annually and at the national level. However, we want the evidence presented here to be comparable with in analyses later in the paper, where we exploit both between-newspaper variation and variables that are available at the quarterly resolution (as is our dependent variable). Consequently, our unit of analysis is the newspaperquarter. In order to better match the income data to the unit of analysis, we adopt a procedure akin to that of Palmer and Whitten (1999), whereby we calculate annual growth rates, assign those to the third quarter of each year, and then linearly interpolate the remaining quarterly growth rates. In Supplementary Table B11, we show that the inferences displayed in Figure 2 are unaffected if we, instead, replicate the annual growth rates four times - one for each quarter - for each year.

Notationally, we refer to growth rates of variables with $\delta$ and first differences with $\Delta$. The percentile ranges defining each income group are superscripted. We thus denote the growth rate of, say, the first decile of the income distribution as $\delta \operatorname{Inc} c^{P 0-10}$.

We employ multivariate analysis so that we can assess the correlation between news tone

\footnotetext{
${ }^{11}$ As of July, 2020, Piketty and Saez (2003) had been cited 1,164 times in the Web of Science. Burkhauser et al. (2012) discuss the strong correspondence between Piketty and Saez's top-income estimates, based on tax records, and confidential survey data on top-incomes held by the U.S. Census Bureau.

${ }^{12}$ Alvaredo et al. $(2017,27-28)$ provide a discussion of the construction of the WID measures.
} 
and each income-growth measure conditional on the other growth measures. This allows us to estimate how closely news tone tracks income growth for one income group above and beyond its correlation with income growth for other groups. However, this analytical goal, together with the structure of our data, raises the potential for inferences to be undermined by either or both of temporal and spatial autocorrelation in the errors. A common approach to dealing with temporal autocorrelation is to introduce one or more lagged dependent variable (LDV) terms. An LDV is justified if we believe that the tone of economic news is path dependent such that news tone at $t$ affects news tone at $t+1$. At the same time, there are concerns about this kind of specification in the presence of unit fixed effects (Plümper and Troeger 2019), which we believe belong in the model. An alternative approach is to treat the two types of autocorrelation as nuisance to be corrected for, thus removing the need for inclusion of LDVs. Under both approaches, corrections can also be applied to account for spatial autocorrelation.

As we do not wish our inferences to be driven by model specification choices in this regard, we present results from both (a) a heavily dynamic specification, with four lags of the DV, and (b) a static specification that explicitly adjusts standard errors for correlation across panels and autocorrelation up to four lags. ${ }^{13}$ We provide a more extended discussion of estimation issues in Supplementary Section B2.

The analysis proceeds in three steps. First, we examine the association of economic news tone with income growth for each income quintile in the population. Next, we zero in on top incomes and assess the correlation between news tone and income growth for the highest income quantiles, as compared to and conditional on income growth at the bottom and middle of the income spectrum. Finally, we conduct a formal statistical test for the presence of pro-rich bias in the economic news.

\footnotetext{
${ }^{13}$ All models include newspaper-specific intercepts and trends, as well as quarter-of-year dummies. The dynamic specifications use the standard-error correction proposed by Beck and Katz (1995), while the static specifications use the correction proposed by Driscoll and Kraay (1998).
} 


\section{Tone-Growth Associations by Income Quintile}

We begin by regressing tone on the growth rates of each income quintile, allowing us to observe the partial correlation between tone and growth in one part of the distribution conditional on growth in all other parts. As will become apparent, there are some very high correlations between these by-quintile growth rates, ${ }^{14}$ so we take care to estimate models that do not yield inferences driven by multicollinearity-inflated standard errors. Most importantly for our core goal, the distinctiveness of change in the fortunes of those with the highest incomes means that our inferences regarding these groups suffer much less from this problem.

An initial set of descriptive results, from models that include income growth rates for each income quintile, are presented in Figure 2. We display here separate estimates from our dynamic and static specifications. ${ }^{15}$ While estimates vary by model specification, several patterns emerge.

We start by focusing on the top two estimates for each quintile, which represent models (dynamic and static, respectively) in which all five quintiles are included. First, we find no evidence that the income growth of the poorest $40 \%$ of the population has any association with the tone of economic news. Second, we observe evidence of a positive association between income growth around the median (third quintile) and news tone, together with a negative association for the income growth of the fourth (i.e. second-richest) quintile. These two results, however, must be interpreted with caution because of an exceptionally high bivariate correlation between income growth for the third and fourth quintiles $(r=0.96)$. This very high correlation likely explains the particularly wide confidence intervals for these two sets of estimates and makes it doubtful that the partial correlations for these two quintiles can be reliably separated from one another when both are included in the model. We thus re-estimate the associations with models that exclude, one at a time, each of the third and fourth quintiles. These models yield more precise point estimates for these two quintiles. The estimates for these quintiles, furthermore, are either indistinguishable from zero or, in the case of quintile- 4 growth in the static model, negatively signed.

\footnotetext{
${ }^{14}$ Supplementary Tables A12 and A10 provide the correlation matrices of the decile and quintile growth rate variables, respectively.

${ }^{15}$ See Supplementary Tables B9 and B10 for the full results.
} 
Finally, across all specifications, income growth for the top quintile displays a reliably positive association with news tone. Indeed, it is the only quintile for which this - or anything even close to it - is true. Note, too, that the top-quintile point estimates appear small only because they are plotted on a scale that must accommodate the wide confidence intervals on other estimates. The correlations are, in fact, substantively large: depending on the specification, a standarddeviation difference in income growth for the top quintile (0.03\%), holding growth in the other income groups constant, is associated with a $14-21 \%$ of a standard-deviation difference in news tone (instantaneously). To give a sense of scale, economic recession is on average associated with a $43 \%$ of a standard-deviation drop in news tone during this period. ${ }^{16}$

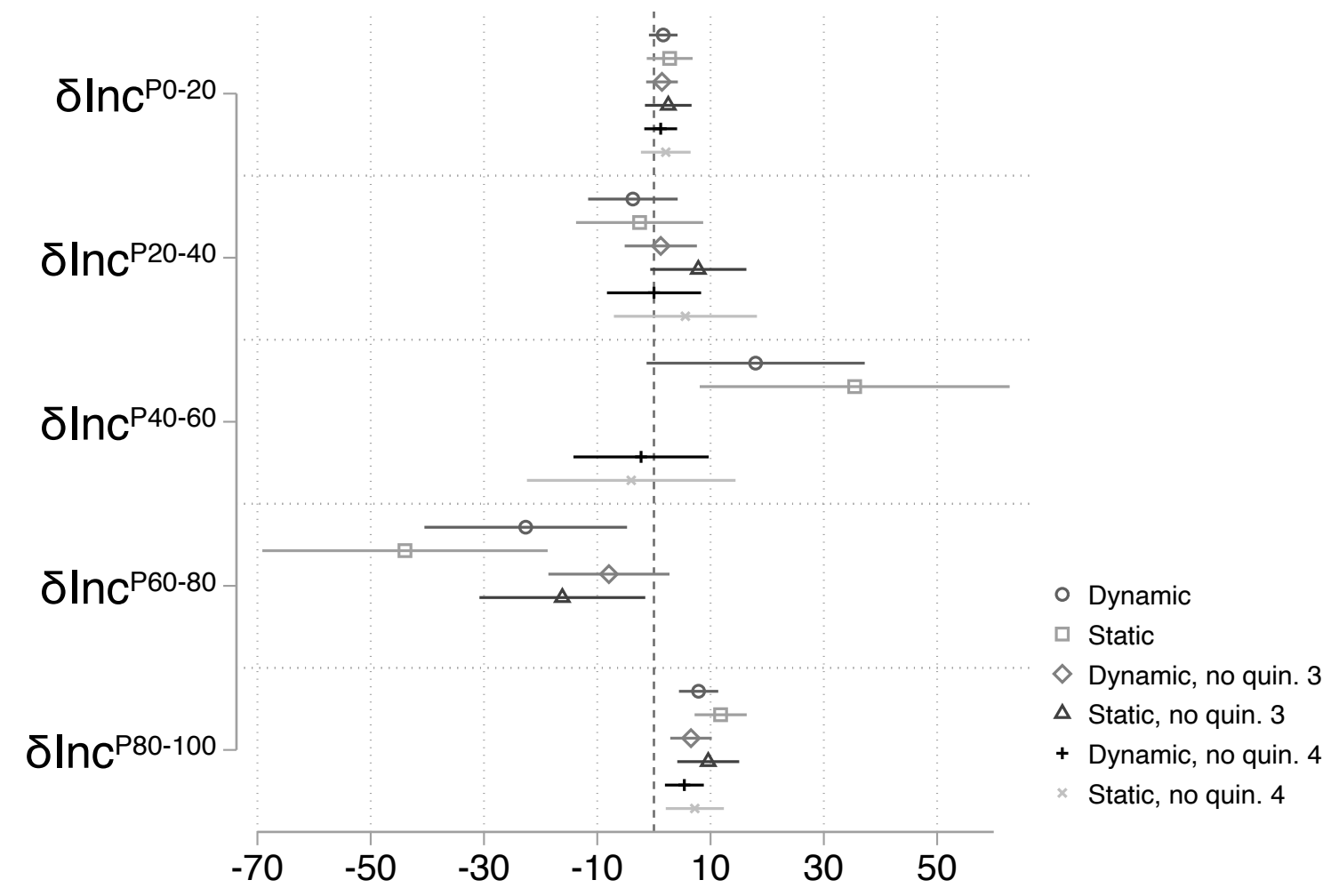

Figure 2: Descriptive inferences regarding association between economic news tone and income growth for each quintile in the income distribution. Full results in Supplementary Tables B9 and B10.

\footnotetext{
${ }^{16}$ See Supplementary Table B8.
} 


\section{Tone-Growth Associations for Top-Income Groups}

The analyses presented so far simplify interpretation by assessing how economic news tone relates to the welfare of a set of equal-sized income groups collectively covering the entire income spectrum (except where noted). Given the extreme concentration of incomes at the high end of the income scale in recent decades, however, we might wonder whether the association between top-quintile income growth and news tone is in fact driven by income growth at the very top of the distribution, i.e., in the topmost slice of the top quintile (say, the top $5 \%$ or top $1 \%$ ). A question of key normative importance is whether the economic news more closely tracks the fortunes of the very rich, in particular, than the fortunes of other income groups.

As a first step in answering this question, we seek to get a good estimate of the association between top-income growth and news tone, for various slices of the top end of the distribution. We do so by estimating a set of models including growth rates for different top-income quantiles. As we saw in Figure 2, there are non-trivial issues of multicollinearity across the income-growth measures for various parts of the income distribution. Our primary interest for this next set of analyses is in assessing tone-associations with top-income growth, rather than estimating the (multicollinearity-afflicted) associations of news tone with growth for each of the other parts of the income distribution. Consequently, to mitigate multicollinearity issues, we adopt a core specification that includes bottom-quintile growth and middle-quintile growth, and then add the various top-income growth measures across different models. We exclude fourth-quintile growth because of the severe multicollinearity issue that arises when including both this quintile and the middle-quintile; this choice maximizes the prospects of finding an association between news tone and growth at the theoretically important median. We also exclude the second quintile given the evidence of noisy estimates for this quintile in Figure $2 ;^{17}$ lower incomes are thus represented in these models by the bottom quintile. Finally, as the evidence from Figure 2 indicates that inferences are not meaningfully driven by the use of the dynamic versus the static specification of our models, for presentational simplicity we adopt only the former from this point.

\footnotetext{
${ }^{17}$ This imprecision is driven by relatively high correlations with bottom- and middle-quintile income growth, as shown in Supplementary Table A10.
} 
Figure 3 shows the core estimates from these top-income models. for full results. In each of the four models, we include a different top-end income quantile: top-10\%, top-5\%, top-1\%, or top- $0.1 \%$. These results strongly suggest that the top-quintile growth association with news tone is in fact driven by income growth within the top decile. ${ }^{18}$ Indeed, there is remarkable stability in the estimated top-income coefficients as we move through models focusing on increasingly small top-end income groups. To give a sense of magnitude, a one standard-deviation change in income growth rates for the top 1 percent is associated with an (instantaneous) change in news tone of $11 \%$ of a standard deviation, compared to $43 \%$ for a recession. Moreover, we continue to see in these models no statistically significant association between middle- or bottom-quintile income growth and news tone. In short, Figure 3 provides fairly robust evidence that top-income growth is consistently statistically associated with news tone - and no such evidence for income growth of the poor or an approximation of the median income earner.

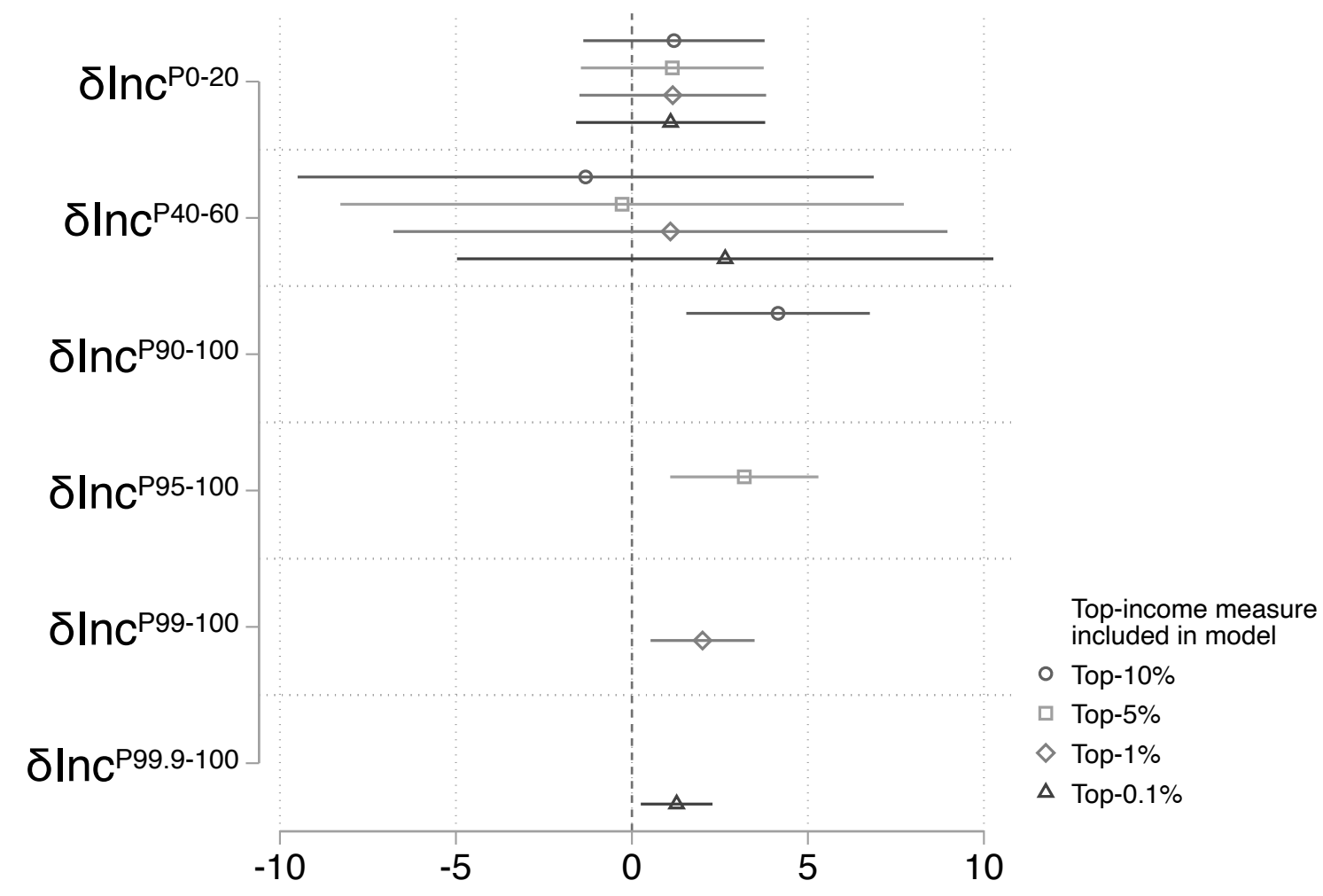

Figure 3: Descriptive inferences regarding association between economic news tone and income growth at various points in the income distribution. Full results in Supplementary Table B14.

\footnotetext{
${ }^{18}$ Supplementary Table B15 reinforces this point by showing estimates of the same set of models that also include income growth for the 80-90 income group. These estimates show that there is little evidence of the top-quintile association from Figure 2 being driven by the lower half of that quintile. However, because $\operatorname{corr}\left(\delta \operatorname{Inc} c^{P 40-60}, \delta \operatorname{Inc} c^{P 80-90}\right)=0.91$, the confidence intervals on those coefficient estimates are large.
} 


\section{Assessing Pro-Rich Bias in News Tone}

Having assessed the partial correlations between top-end, median, and low-end income growth rates and news tone, we turn now to assessment of the presence and degree of income-group bias in news-tone movements.

We note first that the above results cannot speak directly to this issue. One reason is that, in a normative sense, the coefficients for the different income groups should be re-scaled to reflect the relative sizes of the populations to which they correspond. We can see the issue most clearly if we think of the relationship between news tone and groups' welfare as akin to one of representation. Let us assume a normative democratic ideal in which every resident's economic welfare should receive equal weight in any account or assessment of the state of the economy. Under this normative standard, we would expect the material wellbeing of equal-sized groups to receive roughly equal "representation" in reporting on the economy; and we would, likewise, expect larger groups to receive greater weight in the economic news than smaller groups. Thus, for instance, if we observed that the economic news was roughly as well correlated with welfare changes for the top $1 \%$ as with welfare changes for the bottom $20 \%$, we would, against this normative benchmark, be observing a descriptive bias in the economic news in favor of the top $1 \%$ relative to the bottom fifth.

In Supplementary Section A4, we demonstrate this logic algebraically. That analysis also shows that the relevant inference when comparing the strength of the association between news tone and income growth at two different parts of the income distribution is not whether the coefficients are statistically distinguishable from each other in magnitude, but rather whether their ratio is statistically distinguishable from the ratio of the underlying proportions of the population captured by each part of the income distribution. When comparing income quintiles (i.e. where the income groups are equally sized), this collapses to a comparison of the raw coefficients. However, when comparing the income growth of, say, the top $1 \%$ against the bottom 20\%, we must account for the fact that the latter group is 20 times larger than the former and so, under a normative baseline of equal tone-responsiveness across income groups, should have a coefficient that is 20 times larger. Given this logic, we focus on presenting the 
estimated ratios of relevant coefficients, rather than the raw coefficients themselves (which are available in Supplementary Table B16).

On this basis, we estimate models that allow us to assess the degree of descriptive pro-rich bias in news tone. The core specification that we adopt here contains income-growth rates for three income groups: the bottom-20\%, the top- $X \%$, and the broad middle from the 20th percentile to the lower threshold of the top-X\% group - where we estimate models with $X \in$ $\{10,5,1,0.1\}$ to assess the robustness of the inferences to progressively narrower conceptions of "top income." This core specification allows us to achieve coverage of income growth across the full income distribution, ensuring that the proof for the inferential test of coefficient ratios (derived in Supplementary Section A4) applies, while avoiding the high levels of multicollinearity that arise from including a large number of income groups. Breaking out the bottom-20\% from the broad middle, further, allows the opportunity for a normatively interesting comparison of the relationship between news tone and top-income, broad-middle-income, and bottom-income growth, respectively.

We separately present results for a comparison of the broad-middle to the top (Figure 4a), and for a comparison of the bottom to the top (Figure 4b). For each top-income measure, the circle represents the estimated ratio of news tone's association with income growth in the broad middle to news tone's association with income growth for the top-income group. We see that, in Figure 4a, for all four top-income measures, the ratio of tone's association with middle-income growth to tone's assocation with top-income growth is statistically indistinguishable from zero. Meanwhile, the diamonds represent the group-size-based normative baseline of unbiasedness for each top-income measure. We do not plot the diamonds for the top- $0.1 \%$ models because these values (799 for Figure 4a and 200 for Figure 4b) would be located so far to the right that the $\mathrm{x}$-axis scales would be too large to clearly read off the inferences for the other topincome groups. The core message of Figure $4 \mathrm{a}$ is that, across all four top-income measures, the estimated ratios are much lower than the normative baseline: in other words, news tone's association with top-income growth is far stronger, relative to that with middle-income growth, than would be expected on the basis of an equal weighting of the welfare of individuals across 
the income distribution. As the confidence intervals indicate, the inferences in this regard are extremely clear. Figure 4b displays, with respect to the bottom-top comparison, a remarkably similar pattern of stark over-representation of the welfare of the very rich in the tone of the economic news.

As we have estimated models using national-level economic indicators, one potential concern might be a form of ecological fallacy: the subnational regions in which inequality is rising might not be the regions in which positive economic news is being reported. Compositional effects could thus lead national-level inferences astray if we operate only with national economic measures. In Supplementary Section A5, we show that matching newspapers to state-level distributional income-growth data - calculated using the same methodology as employed for our national data (Sommeiller, Price, and Wazeter 2016) - yields the same inferences of pro-rich bias in news tone at the state level as we find using national-level data.

In summary, the descriptive pattern is one in which voters are receiving a portrait of the national economy that, to a stunning degree, over-represents the economic experiences of those with the highest incomes. Given the stability of this inference across different definitions of the top-income group, the estimations in the remainder of the paper operationalize the top-income group as the top-1\% (i.e. P99-100). This choice avoids a large proliferation of models while focusing inferences on a subset of the population that is undeniably extremely affluent.

\section{Explaining Class Bias in Economic News}

We turn now to explanations for the normatively troubling association between economic news tone and top-income growth. We focus first on examining empirical implications of the central mechanism we have theorized, in which a journalistic focus on covering the business cycle interacts with the distributional structure of aggregate gains and losses in the economy. We next examine evidence for alternative explanations grounded in the costs of news production and in news producers' or consumers' distributional preferences. The models presented in this section all deploy our dynamic panel specification from the previous section, with newspaper-quarters 


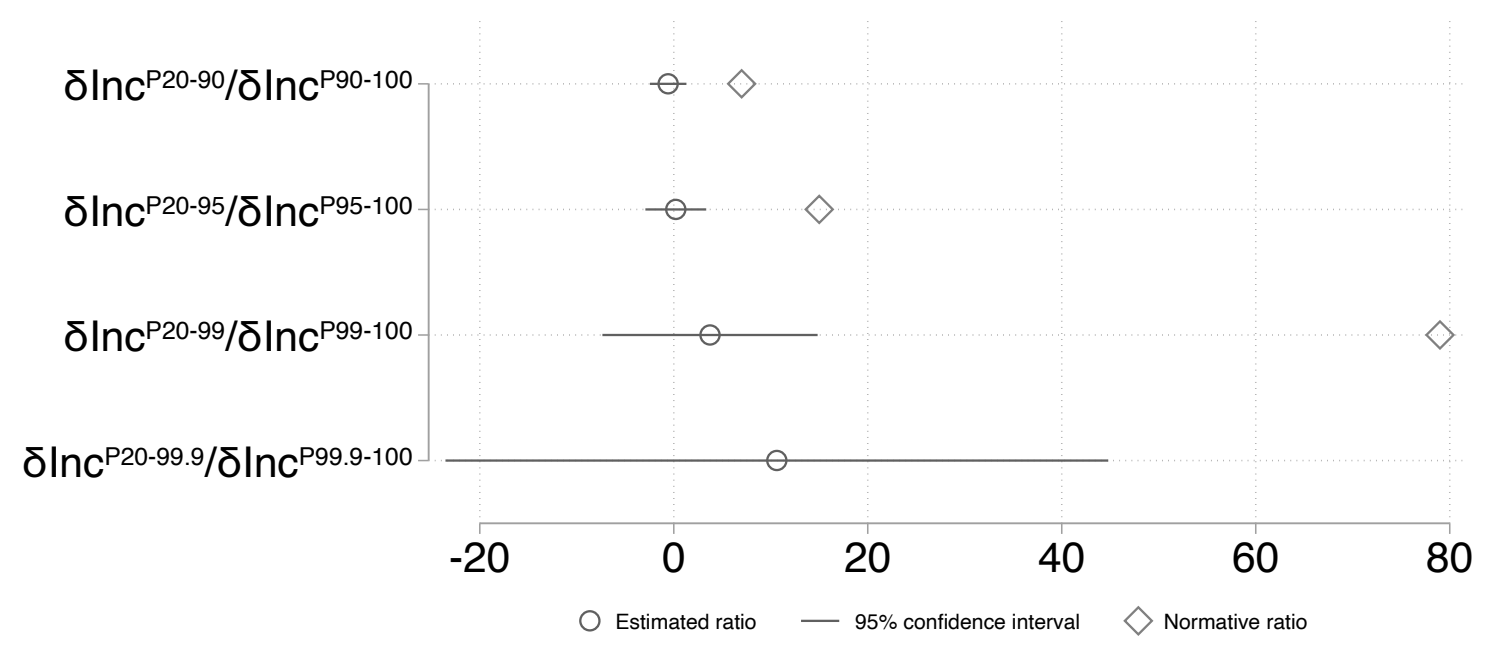

(a) Top-income growth versus broad middle-income growth measures. Normative baseline for top- $0.1 \%$ model is 799 (not plotted).

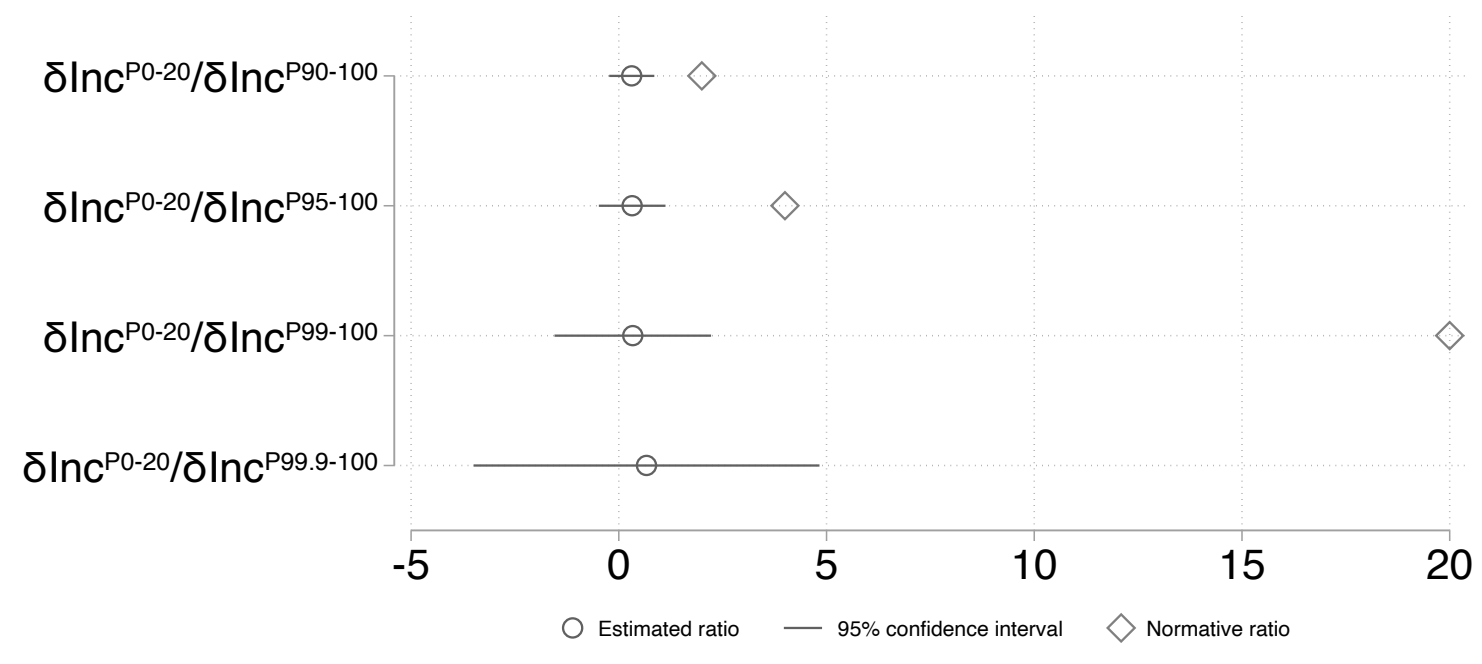

(b) Top-income growth versus bottom-quintile income growth measures. Normative baseline for top- $0.1 \%$ model is 200 (not plotted).

Figure 4: Estimated coefficient ratios from models predicting economic news tone with income growth for different parts of the income distribution. Diamonds indicate normative baseline for each coefficient ratio, assuming the normative standard of an equal per capita association with news tone for all income groups. Normative baselines for top- $0.1 \%$ models not plotted to avoid unhelpful scaling of x-axis. Underlying results in Supplementary Table B16. 
as the unit of observation. Supplementary Section A1 provides full details of the sources of variables used in this section.

\section{Economic News as Business-Cycle Coverage}

Can the upward class bias in economic news be explained in part by the news media's tendency to track the business cycle? We address this question by testing empirical predictions of the two structural causal models presented in the theory section.

\section{Macroeconomic Aggregates}

In causal model 1 , the drivers of economic growth simultaneously cause aggregate expansion (i.e., growth and employment) and higher inequality. Meanwhile, higher growth and lower unemployment generate more positive economic news.

We can derive multiple predictions from this logic. First, news tone should be positively correlated with inequality. Second, news tone should be correlated positively with GDP growth and negatively with unemployment rates. A third prediction - one more specific to the aggregatecentered-journalism explanation for class-biased economic news - is that any correlation between inequality and news tone should be weaker conditional on the macroeconomic aggregates than it is unconditionally. In the language of Pearl (2009), conditioning on the macroeconomic aggregates should, under this causal model, "block" the path running between news tone and inequality, eliminating any correlation between the two that arises from this path (while potentially preserving other sources of correlation not captured in the model). ${ }^{19}$

We test these predictions at the national level via a set of models reported in Table $1 .^{20}$ We begin by translating the descriptive results for quantile-specific income growth rates, reported in the previous section, into a corresponding summary result for change in income inequality.

\footnotetext{
${ }^{19}$ The inferences we draw from these analyses are, however, conditional on the posited direction of the model's causal arrows.

${ }^{20}$ Supplementary Table B18 presents the equivalent set of models, without dropping bottom and middle quintile income growth, and shows the inferences for these latter coefficients are not influenced by inclusion of macroeconomic predictors.
} 
To the extent that the news is more responsive to income gains and losses for the rich than to those for the non-rich, positive news tone should also be positively correlated with changes in income inequality in the form of changing income shares for the very rich. We demonstrate this point empirically in Models 1 and 2. Model 1 shows, consistent with results presented in the last section, that news tone is strongly and positively correlated with income growth for the top 1 percent, conditional on income growth in the middle and bottom quintiles, and that news tone is uncorrelated with growth at the bottom and in the middle of the income scale. Model 2 then directly estimates the association of news tone with changes in income inequality, defined here as growth in the top-1 percent's income share. Consistent with the first prediction, above, we observe a positive and precisely estimated association between news tone and change in top-end income inequality.

In Model 3, we add current-quarter GDP growth to the equation alongside change in top1-percent income share. Consistent with the second prediction from the causal model, we see that GDP growth is a powerful, positive predictor of news tone. Further, consistent with the third prediction, we see that conditioning on GDP growth dramatically reduces the original correlation (from Model 2) between news tone and change in top-1-percent income share, cutting the coefficient in half. In Model 4, we test the same two predictions with respect to GDP growth's close correlate, the unemployment rate. Placing change in the unemployment rate on the righthand side of the model, alongside change in top-income share, we see that unemployment change is a strong negative predictor of news tone (second prediction) and that its inclusion in the model similarly slashes the correlation between news tone and top-income share in half (third prediction). In Model 5, we include both macroeconomic indicators in the model, achieving a further reduction in the tone-inequality association.

We also note that the estimated effect of GDP growth is substantially reduced by the inclusion of unemployment in the model. One possible reason is that unemployment coverage swamps GDP coverage because the unemployment rate is officially reported more frequently (monthly) than the growth rate (quarterly). A second possibility is that the effect of GDP growth on news tone is partly mediated by change in unemployment. Journalists might directly attend more to 
employment because of its seemingly more direct relationship to households' material welfare.

To be clear, the model estimates that we present cannot tell us whether journalists are reporting on either of the particular indicators in our analyses. They may well be doing so. Yet the results are also consistent with journalistic coverage of any number of close correlates of aggregate expansion and contraction, such as business or consumer confidence, retail sales, manufacturing activity, inventories, interest rates, or corporate performance. When reporters cite these auxiliary measures, they are typically doing so in an effort to characterize the overall state of the economy. Whether journalists have taken their cue from growth or unemployment figures themselves or from various "leading" or "lagging" indicators, they appear to have been tracking aggregate processes of recession and recovery that, at least in recent decades, have been concentrating losses and gains, respectively, at the very top of the income scale.

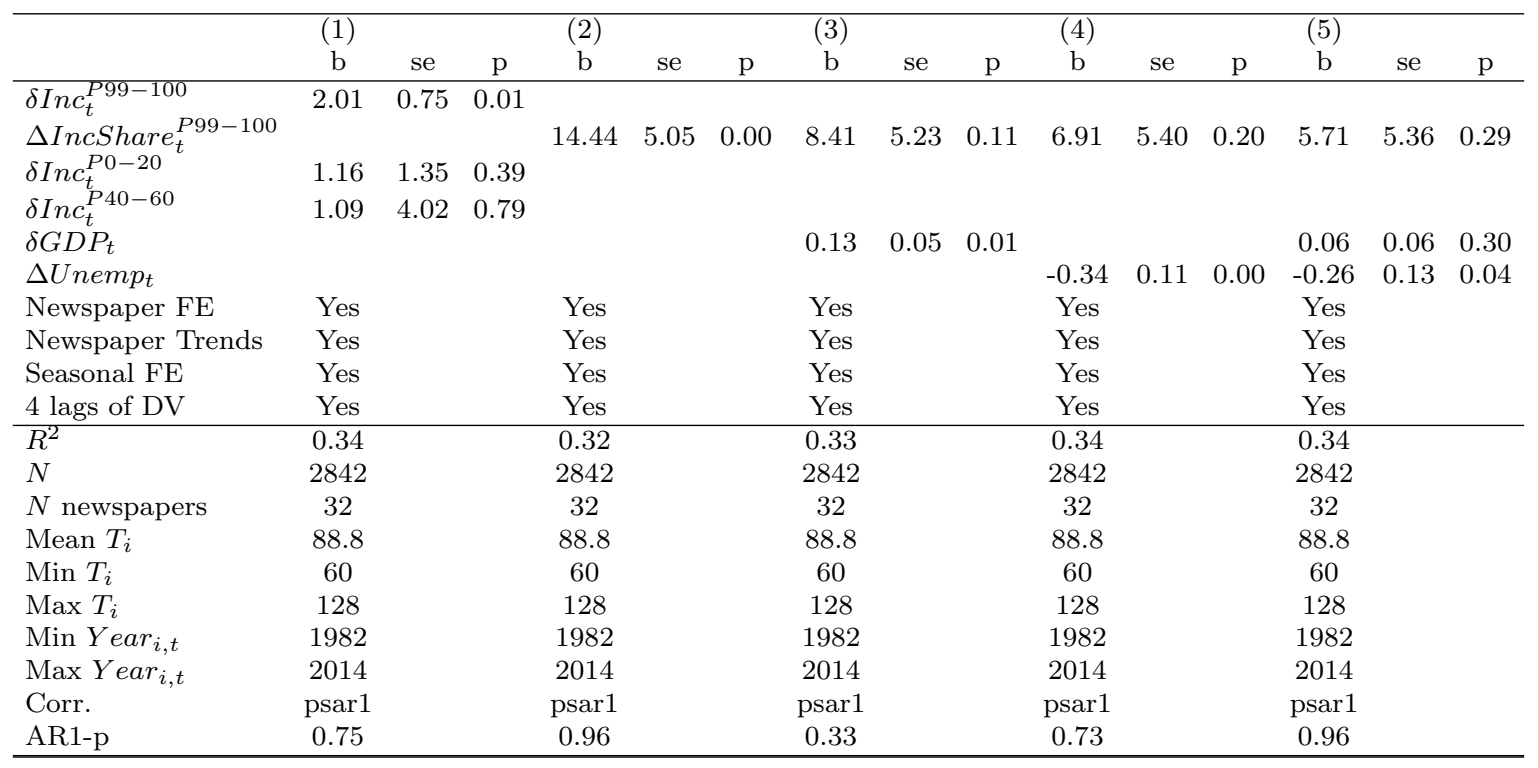

Table 1: Estimates of association between economic news tone and aggregate economic variables. OLS with panel-corrected standard errors.

\section{Corporate Performance}

To the extent that journalists seek to report on aggregate economic expansion or contraction, they are likely to attend closely not only to macroeconomic aggregates but also to corporate performance. A thriving corporate sector is commonly seen as a key pillar of economic success. 
In turn, corporate performance, particularly as reflected in share values, is likely to be much more strongly correlated with the fortunes of the rich than with those of the rest of the population, given the strong upward skew in the distribution of share ownership. We have captured this underlying logic in causal model 2.

Causal model 2 has two distinctive empirical implications: (1) corporate performance should be correlated with news tone and (2) controlling for corporate performance should reduce the size of the correlation between top-end inequality and news tone, since conditioning on corporate performance blocks a path connecting these two variables. We capture corporate performance using stock-market indices, for two reasons. First, leading stock-market indices are likely to capture the performance of those corporations whose earnings are most likely to be newsworthy. Second, as discussed above, financial-market developments are likely to be accorded special weight by novelty-seeking news media because they are the most frequently measured national economic phenomena.

In our primary analyses, we measure stock market performance using the New York Stock Exchange Composite Index $\left(N Y S E_{t}\right){ }^{21}$ Table 2 reports tests parallel to those we performed for macroeconomic aggregates. For ease of reference, we provide under Model 1 the previously reported baseline national-level descriptive association between news tone and change in top-1 percent income share. In Model 2, we introduce NYSE growth and observe a strong, positive, and precisely estimated effect. Further, the parameter point-estimate for top income-share change drops by around one third. These results are consistent with a mechanism in which financialmarket movements are both a driver of news tone and generate part of the association between news tone and top-end inequality.

Given that financial market developments are likely to be correlated with growth and unemployment, we cannot assume that each provides independent explanatory purchase on the class bias in economic news. In Models 3 and 4 we thus add, successively, GDP growth and change in unemployment to the model. In Model 4, inclusion of both macroeconomic aggregates further reduces the point estimate for the coefficient on change in top-income share; more than 60 per-

\footnotetext{
${ }^{21}$ Constructed from Moody's NYSE Composite series.
} 
cent of the unconditional association is now gone while the associated standard error remains stable throughout. Meanwhile, both unemployment change and NYSE growth remain strong predictors of news tone; the coefficient on each variable is unaffected by the inclusion of the other. $^{22}$

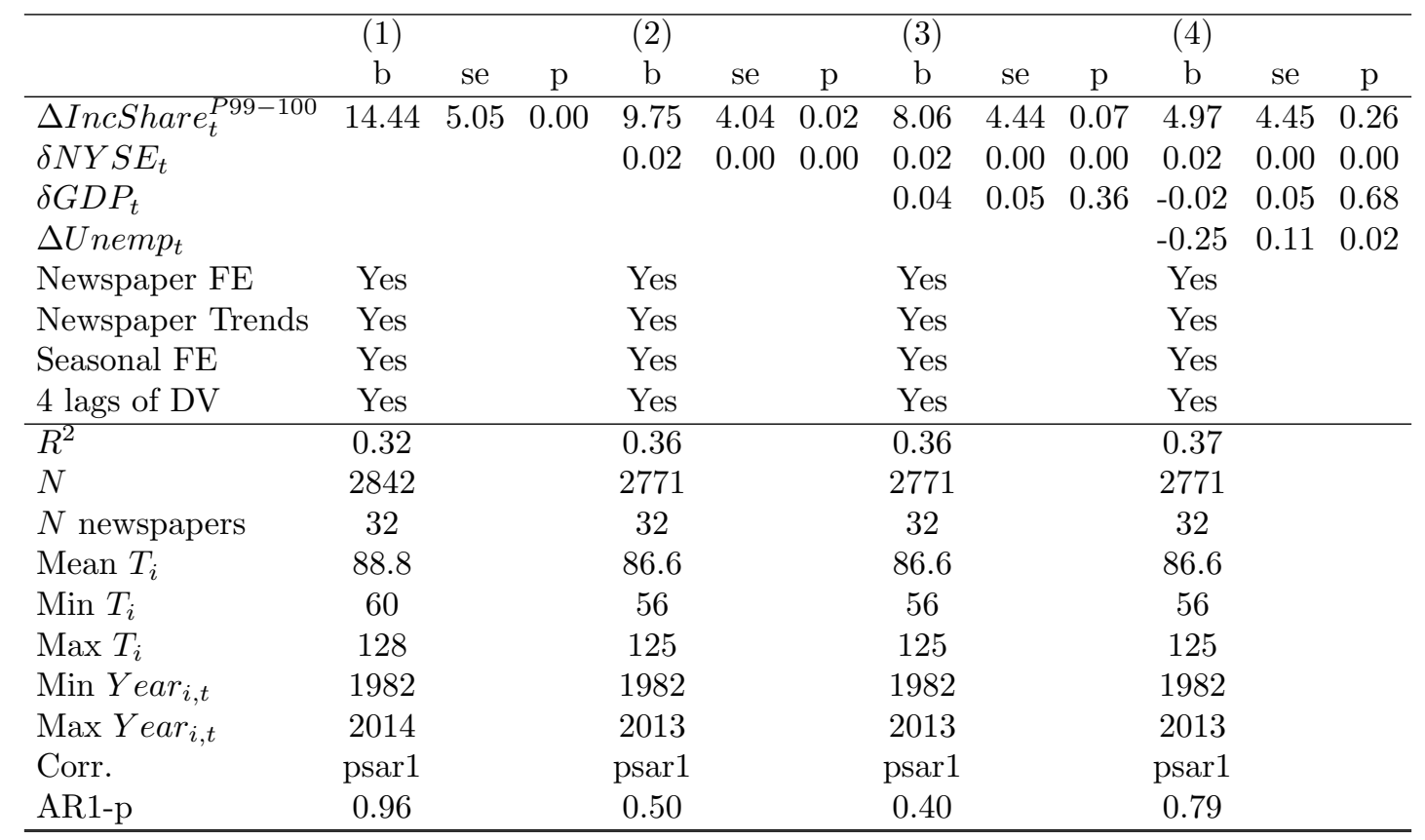

Table 2: Estimates of association between economic news tone, change in top-1 percent income share, growth in NYSE composite index, GDP growth, and change in unemployment. OLS with panel-corrected standard errors.

In sum, we find considerable evidence of the operation of a mechanism in which stock-market gains generate both higher concentrations of income at the top and more positive economic news. We emphasize, further, that we are picking up all effects strictly outside of business sections, where we might reasonably expect a focus on financial markets and developments favoring the most affluent.

Finally, in Supplementary Section A5, we estimate parallel models for macroeconomic aggregates and corporate performance using state-level data. Results for the former are consistent with those using national-level data. For the latter models, we find that a third of the unconditional association between state-level inequality and state-level news tone disappears when NYSE growth is added to the model. Strikingly, all of the unconditional association between

\footnotetext{
${ }^{22}$ In Supplementary Table B19, we show that a very similar pattern holds using the S\&P 500 index.
} 
state-level inequality and state-level news tone disappears when stock market movements and state-level macroeconomic aggregates are included together.

\section{Topic Salience}

The analysis of mechanisms to this point has focused on implications relating to expected conditional correlations between news tone and various economic developments. We turn now to a distinct form of evidence, asking whether the distribution of media attention across economic topics is consistent with our argument.

Figure 5 displays, for a key set of topics, the results of human coding of a random subsample $(N=2000)$ of our sample of economic news articles. ${ }^{23}$ Each article was coded for whether it mentioned each of a wide set of economic phenomena; coding was such that a given article could be coded as mentioning multiple phenomena.

The figure's four panels report results for the four economic developments that have featured on the right-hand side of the statistical models in this paper, displaying for each the proportion of articles over time that mention that topic. Comparing overall levels of attention, we see that employment, corporate performance, and the economy-in-aggregate feature prominently in economic reporting, consistent with our inferences from the models. Most striking, and of central importance to our theoretical claims, is the predominance of references to the economy as an undifferentiated aggregate. Moreover, we see that inequality - defined as any mention of the distribution of or disparities in material resources - receives vanishingly little attention. We extend the analysis in Supplementary Section A6, showing results for a set of additional economic phenomena with distributional implications - average, median, or low-end earnings; poverty and material need; and executive compensation. Of these categories, only poverty and material need are consistently mentioned in more than 10 percent of the sample, and all are far less prominent than mentions of the aggregate economy or corporate performance (see Supplementary Figure A3). On the whole, patterns of topic salience lend considerable support

\footnotetext{
${ }^{23}$ See Supplementary Section A6 for details of the category coding procedure and its reliability. The held-out subsample for the aggregated-economy topic is somewhat smaller $(N=1580)$.
} 
to a theory of economic reporting in which journalists cover the business cycle while failing to attend to who loses or gains as the economy expands and contracts.

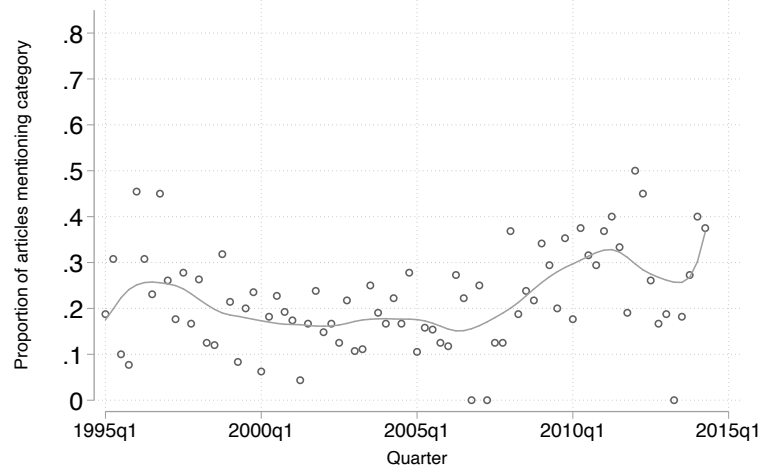

(a) Employment

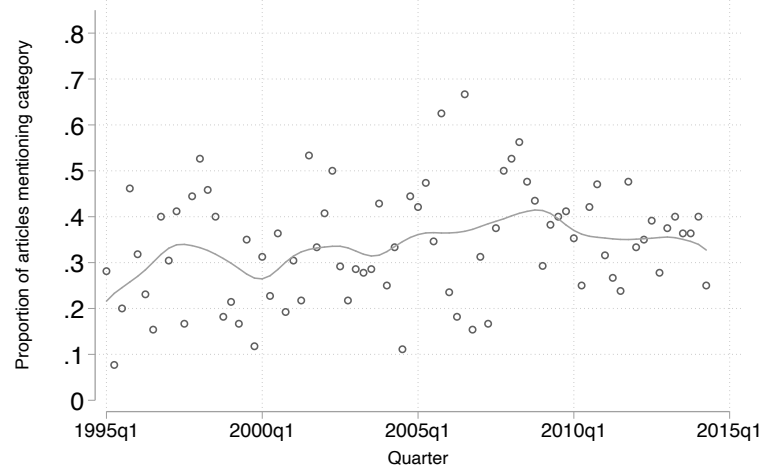

(c) Corporate

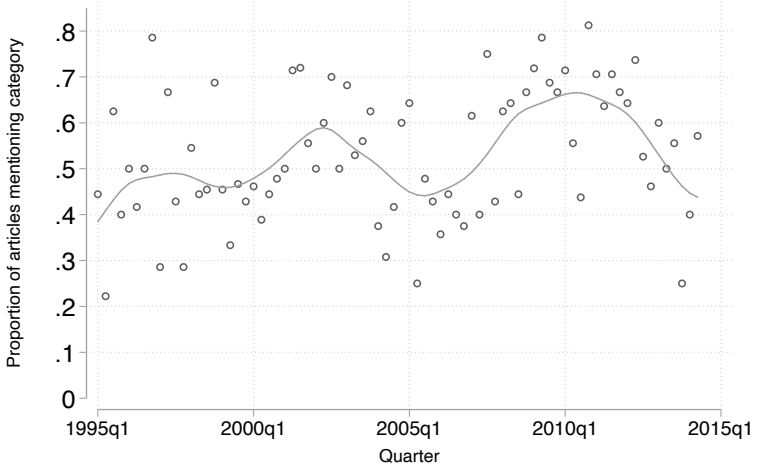

(b) Economy in Aggregate

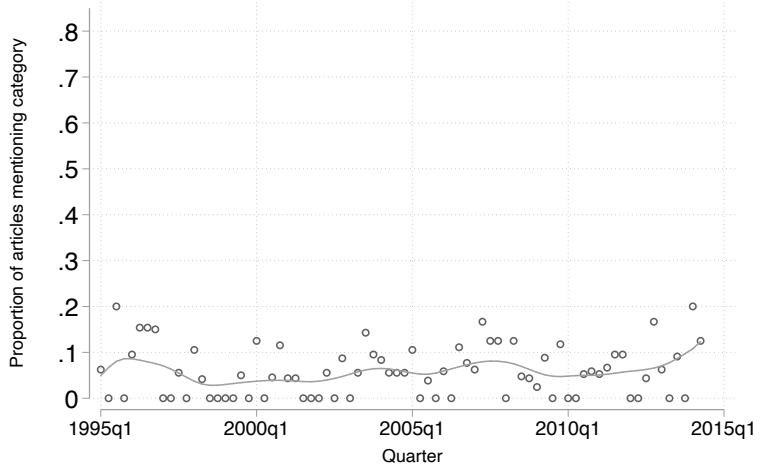

(d) Inequality

Figure 5: Scatter plots of the proportion of newspaper articles mentioning various topics, as categorized by a human coder, by quarter. Lowess curves are shown to smooth noise in each series.

\section{Alternative Mechanisms}

As we previously noted, prior work on skewed patterns of reporting has focused on the interests or preferences of those actors who produce or consume the news. We lack micro-level measures of the distributional preferences of newspaper owners or reporters, which would allow direct tests of these mechanisms. A reasonable proxy for those preferences, however, is the measure of newspaper "slant" developed by Gentzkow and Shapiro (2010). These authors estimate the similarity between the language used by a news outlet and the language employed by Republican as compared to Democratic lawmakers in the Congressional Record. To the extent that the news reflects owners', journalists', or readers' distributional preferences, those preferences 
should also be reflected in partisan alignments, given the two parties' widely differing stances on distributional issues. Put differently, if class-biased news derives from less-egalitarian motives or attitudes among those who direct, produce, or consume the news, that class bias should be stronger among more Republican-aligned newspapers than among more Democratic-aligned newspapers.

In Supplementary SectionA7, we report analyses testing for the moderating effect of partisan slant on class bias in economic news coverage. We find that Democratic-leaning newspapers are no less likely to deliver class-biased economic news than are Republican-leaning outlets, suggesting it is unlikely that class-biased reporting arises from editorial or owner preferences that favor the interests of the rich.

We might also consider a variant of our "covering the business cycle" logic that focuses more on the costs of news production than on pervasive understandings of the economy. Growthoriented reporting might emerge from editors' and reporters' need to economize on time and other resources. Just as Dunaway and Lawrence (2015) argue that "game frame" campaign reporting is less costly than issue-oriented reporting (45), it may be cheaper for news rooms to track aggregate economic developments than to dig into distributional dynamics beneath the surface. Reporters may, thus, operate on a "covering the business cycle" model not because of its strong postwar track record or deep cognitive embeddedness, but because it is a low-cost method of summarizing economic complexity.

We can test for this possibility by exploiting variation in the strength of economizing pressures across newspapers and over time. Dunaway and Lawrence (2015) argue that news organizations that are owned by publicly traded corporations - under pressure to meet earnings targets and boost share values - face stronger short-run profit-seeking imperatives and cost-cutting pressures than privately-held outlets. Thus, if class-biased reporting emerges from a focus on aggregates as a lower-cost news-production model, we should expect this bias to be stronger for newspapers owned by publicly traded companies than for privately held companies. We should further expect the bias, and the conditioning effect of ownership, to be stronger after about 2000, when the sector as a whole saw a reversal of fortune as print revenues began to plunge. 
We report details and results of national and state-level models, interacting public-company ownership with aggregate economic indicators and top-income shares in both the full period and post-2000, in Supplementary Section A7. ${ }^{24}$ Across the specifications tested, we see little evidence that a focus on aggregates is concentrated among newspapers under greater cost-cutting or profit-maximizing pressures. The one exception appears to be a greater focus on statelevel mean-income growth among newspapers owned by public companies (Models 3 and 4, Supplementary Table A19). This greater focus on mean income, however, does not cash out as greater class bias for this group of newspapers, as we see in the lack of an interaction with state-level top-income shares in Supplementary Table A19 (Models 3 and 4). These results as a whole provide little support for the notion that class-biased news emerges from cost-cutting journalistic methods.

\section{Conclusion}

A class-biased informational environment, shaped by skewed economic news, may partially reconcile the fact of rapidly mounting economic inequality with nominal political equality. More specifically, the paper's findings provide a possible explanation for the puzzling pattern of classbiased economic voting in the U.S. (Bartels 2008). It is not terribly surprising that non-rich voters more strongly support incumbents overseeing rising income concentrations at the top if the favorability of the news environment systematically tracks the relative welfare of the rich. ${ }^{25}$

The argument also has implications for the longer-term dynamics of inequality, pointing to a mechanism of positive feedback that could perpetuate distributional biases. The starkly skewed distribution of the fruits of economic growth in the U.S. is, at least partially, the outcome of political battles won by groups representing the interests of the richest Americans (Hacker and Pierson 2011; Saez and Zucman 2019). Yet the more unequally growth is distributed, the less informative aggregate-focused economic news becomes about economic developments affecting

\footnotetext{
${ }^{24}$ We thank Johanna Dunaway for sharing data that forms part of our ownership measure.

${ }^{25}$ The evidence for the role of national economic outcomes in political evaluations is considerable (Lewis-Beck 1988; Duch and Stevenson 2006). Even Healy, Persson, and Snowberg (2017), who present compelling evidence of the role of personal economic fortunes in voting behavior, find that sociotropic evaluations matter about equally.
} 
lower- and middle-income voters. Non-rich voters are likely, in turn, to become less well informed about their distributional interests, facilitating further downstream political victories by the most affluent.

Importantly, the preceding logic cuts both ways: whereas aggregate-focused economic news may compound the prior political victories of the most affluent, distributionally-sensitive economic reporting has the potential to undo those same dynamics. Economic data to support such reporting exist, including Census Bureau estimates of median incomes and poverty rates. Yet distributional indicators are released infrequently - often only annually - which, in a news environment biased toward change, disadvantages these data by comparison with, for instance, the unemployment rate (released monthly) or the stock market (tracked continuously each business day). More frequent releases of distributional measures by government statistical agencies would likely facilitate economic reporting that is better attuned to the welfare of low- and middle-income households.

One possible way of building on the present analysis would be further geographic disaggregation within the U.S. While we have established national and state-level relationships, inequality time-series at lower levels are emerging. ${ }^{26}$ Their extension, together with content from a broader set of local newspapers, would enable examination of how local reporting responds to differential material gains and losses of local income groups and provide additional leverage for causal inference.

A second direction would investigate whether class-biased economic news explains a disconnect between distributional outcomes and citizen demands in a broader set of capitalist democracies (Hicks, Jacobs, and Matthews 2016; Milanovic 2000; Kenworthy and McCall 2008). Findings from Parker and Vissing-Jorgensen (2010) suggest that the relationships we uncover in the U.S. might unfold in other countries, but to varying degrees. Across a set of 10 countries, they find that growing top $1 \%$ income shares are associated with the increasing pro-cyclicality of top- $1 \%$ incomes. If top-end pro-cyclicality and growing income differentials indeed travel together, the implications for distributional politics are sobering: a media that covers the business

\footnotetext{
${ }^{26}$ Sommeiller, Price, and Wazeter (2016) currently provide county and CBSA observations only for 2010-2015.
} 
cycle will generate a stronger pro-rich skew in news content precisely in those contexts where class-biased reporting will be most misleading - where the fortunes of the rich diverge most sharply from the fortunes of the rest.

\section{Disclosures}

The authors affirm this research did not involve human subjects. The authors declare no ethical issues or conflicts of interest in this research. Data and code for reproducing the findings of this study are openly available in the APSR Dataverse at https://doi.org/10.7910/DVN/Q9E8RF.

\section{References}

Aghion, Philippe, Eve Caroli, and Cecilia Garcia-Penalosa. 1999. "Inequality and economic growth: the perspective of the new growth theories". Journal of Economic Literature 37 (4): 1615-1660.

Alvaredo, Facundo, Lucas Chancel, Thomas Piketty, Emmanuel Saez, and Gabriel Zucman. 2017. Global Inequality Dynamics: New Findings from WID.world. Working Paper 23119. National Bureau of Economic Research.

Baccaro, Lucio, and Jonas Pontusson. 2016. "Rethinking Comparative Political Economy: The Growth Model Perspective". Politics 8 Society 49 (2): 219-252.

Barberá, Pablo, Amber E. Boydstun, Suzanna Linn, Ryan McMahon, and Jonathan Nagler. 2021. "Automated Text Classification of News Articles: A Practical Guide". Political Analysis 20 (1): $19-42$.

Bartels, Larry M. 2008. Unequal Democracy: The Political Economy of the New Gilded Age. Princeton, NJ: Princeton University Press.

Beck, Nathaniel, and Jonathan N. Katz. 1995. "What to do (and not to do) with Time-Series Cross-Section Data". American Political Science Review 89 (3): 634-647. 
Bivens, Josh, and Heidi Shierholz. 2018. What labor market changes have generated inequality and wage suppression? Tech. rep. Economic Policy Institute.

Blood, Deborah J., and Peter C. B. Phillips. 1995. "Recession Headline News, Consumer Sentiment, The State of the Economy and Presidential Popularity: A Time Series Analysis 1989-1993". International Journal of Public Opinion Research 7 (1): 2-22.

Boydstun, Amber E., Benjamin Highton, and Suzanna Linn. 2018. "Assessing the Relationship between Economic News Coverage and Mass Economic Attitudes". Political Research Quarterly 71 (4): 989-1000.

Burkhauser, Richard V., Shuaizhang Feng, Stephen P. Jenkins, and Jeff Larrimore. 2012. "Recent Trends in Top Income Shares in the United States: Reconciling Estimates from March CPS and IRS Tax Return Data". Review of Economics and Statistics 94 (2): 371-388.

Cutler, David M., and Lawrence F. Katz. 1991. "Macroeconomic performance and the disadvantaged". Brookings Papers on Economic Activity, no. 2: 1-74.

De Boef, Suzanna, and Paul M. Kellstedt. 2004. "The political (and economic) origins of consumer confidence". American Journal of Political Science 48 (4): 633-649.

Driscoll, John C., and Aart C. Kraay. 1998. "Consistent Covariance Matrix Estimation with Spatially Dependent Panel Data". Review of Economics and Statistics 80 (4): 549-560.

Duch, Raymond M., and Randy Stevenson. 2006. "Assessing the magnitude of the economic vote over time and across nations". Electoral Studies 25 (3): 528-547.

Dunaway, Johanna, and Regina G. Lawrence. 2015. "What Predicts the Game Frame? Media Ownership, Electoral Context, and Campaign News". Political Communication 32 (1): 4360.

Gans, Herbert J. 2004. Deciding What's News: A Study of CBS Evening News, NBC Nightly News, Newsweek and Time. 25th Anniversary Edition. Evanston, IL: Northwestern University Press.

Garz, Marcel, and Gregory J. Martin. 2020. "Media Influence on Vote Choices: Unemployment News and Incumbents' Electoral Prospects". American Journal of Political Science. Forthcoming. 
Gentzkow, Matthew, and Jesse M. Shapiro. 2010. "What Drives Media Slant? Evidence From U.S. Daily Newspapers". Econometrica 78 (1): 35-71.

Gilens, Martin, and Craig Hertzman. 2000. "Corporate Ownership and News Bias: Newspaper Coverage of the 1996 Telecommunications Act". Journal of Politics 62 (2): 369-386.

Goldin, Claudia, and Lawrence F. Katz. 2007. The race between education and technology: the evolution of US educational wage differentials, 1890 to 2005. Tech. rep. National Bureau of Economic Research.

Guvenen, Fatih, Serdar Ozkan, and Jae Song. 2014. "The nature of countercyclical income risk". Journal of Political Economy 122 (3): 621-660.

Hacker, Jacob S., and Paul Pierson. 2011. Winner-Take-All Politics: How Washington Made the Rich Richer - And Turned Its Back on the Middle Class. Simon \& Schuster.

Hall, Peter A., and David Soskice, eds. 2001. Varieties of Capitalism: The Institutional Foundations of Comparative Advantage. Oxford, UK: Oxford University Press.

Healy, Andrew, Mikael Persson, and Erik Snowberg. 2017. "Digging into the Pocketbook: Evidence on Economic Voting from Income Registry Data Matched to a Voter Survey". American Political Science Review 111 (4): 771-785.

Herman, Edward S., and Noam Chomsky. 1988. Manufacturing Consent: The Political Economy of the Mass Media. Pantheon Books.

Hetherington, Marc J. 1996. "The Media's Role in Forming Voters' National Economic Evaluations in 1992". American Journal of Political Science 40, no. 2 (): 372-395.

Hicks, Timothy, Alan M. Jacobs, and J. Scott Matthews. 2016. "Inequality and Electoral Accountability: Class-Biased Economic Voting in Comparative Perspective". Journal of Politics 78 (4): 1076-1093.

Hopkins, Daniel J., Eunji Kim, and Soojong Kim. 2017. "Does newspaper coverage influence or reflect public perceptions of the economy?" Research \& Politics 4 (4). 
Jacobs, Alan M., J. Scott Matthews, Timothy Hicks, and Eric Merkley. 2021. "Replication Data for: 'Whose News? Class-Biased Economic Reporting in the United States'”. doi:10.7910/ DVN/Q9E8RF.

Kelly, Nathan J., and Peter K. Enns. 2010. "Inequality and the Dynamics of Public Opinion: The Self-Reinforcing Link Between Economic Inequality and Mass Preferences". American Journal of Political Science 54 (4): 855-870.

Kenworthy, Lane, and Leslie McCall. 2008. "Inequality, public opinion and redistribution". Socio-Economic Review 6 (1): 35-68.

Lewis-Beck, Michael S. 1988. Economics and Elections: The Major Western Democracies. Ann Arbor, MI: University of Michigan Press.

Lin, Ken-Hou, and Donald Tomaskovic-Devey. 2013. "Financialization and U.S. Income Inequality, 1970-2008". American Journal of Sociology 118 (5): 1284-1329.

Merkley, Eric. 2019. "Partisan Bias in Economic News Content: New Evidence". American Politics Research 47 (6): 1303-1323.

Milanovic, Branko. 2000. "The median-voter hypothesis, income inequality, and income redistribution: an empirical test with the required data". European Journal of Political Economy 16, no. 3 (): $367-410$.

Mutz, Diana C. 1992. "Mass Media and the Depoliticization of Personal Experience". American Journal of Political Science 36 (2): 483-508.

Nadeau, Richard, Richard G. Niemi, David P. Fan, and Timothy Amato. 1999. "Elite Economic Forecasts, Economic News, Mass Economic Judgments, and Presidential Approval". Journal of Politics 61 (1): 109-135.

Palmer, Harvey D., and Guy D. Whitten. 1999. "The Electoral Impact of Unexpected Inflation and Economic Growth". British Journal of Political Science 29 (04): 623-639.

Parker, Jonathan A., and Annette Vissing-Jorgensen. 2010. The increase in income cyclicality of high-income households and its relation to the rise in top income shares. Tech. rep. NBER Working Paper No. 16577. National Bureau of Economic Research. 
Pearl, Judea. 2009. Causality. 2nd ed. Cambridge University Press.

Piketty, Thomas, and Emmanuel Saez. 2003. "Income Inequality in the United States, 19131998". Quarterly Journal of Economics 118 (1): 1-41.

Plümper, Thomas, and Vera E. Troeger. 2019. "Not so Harmless After All: The Fixed-Effects Model". Political Analysis 27 (1): 21-45.

Saez, Emmanuel. 2016. "Striking it Richer: The evolution of top incomes in the United States (updated with 2015 preliminary estimates)". University of California, Berkeley, Working Paper.

Saez, Emmanuel, and Gabriel Zucman. 2019. The Triumph of Injustice. Norton \& Company.

Sommeiller, Estelle, Mark Price, and Ellis Wazeter. 2016. "Income inequality in the U.S. by state, metropolitan area, and county". Economic Policy Institute. Visited on 10/27/2017. http://www.epi.org/publication/income-inequality-in-the-us/.

Soroka, Stuart N. 2006. "Good News and Bad News: Asymmetric Responses to Economic Information". Journal of Politics 68 (2): 372-385.

— . 2012. "The Gatekeeping Function: Distributions of Information in Media and the Real World". Journal of Politics 74 (2): 514-528.

Soroka, Stuart N., Dominik A. Stecula, and Christopher Wlezien. 2015. "It's (Change in) the (Future) Economy, Stupid: Economic Indicators, the Media, and Public Opinion". American Journal of Political Science 59 (2): 457-474.

Volscho, Thomas W., and Nathan J. Kelly. 2012. "The Rise of the Super-Rich: Power Resources, Taxes, Financial Markets, and the Dynamics of the Top 1 Percent, 1949 to 2008". American Sociological Review 77 (5): 679-699.

Wiczer, David. 2014. "Looking at Recessions through a Different Lens". The Regional Economist. Wolff, Edward N. 2016. "Household Wealth Trends in the United States, 1962 to 2013: What Happened over the Great Recession?" RSF: The Russell Sage Foundation Journal of the Social Sciences 2 (6): 24-43. 
Young, Lori, and Stuart N. Soroka. 2012. "Affective News: The Automated Coding of Sentiment in Political Texts". Political Communication 29 (2): 205-231. 